\title{
Evaluation of peripheral blood levels in patients with chronic and aggressive periodontitis: A clinico- biochemical study
}

\author{
Swaroop Chandy,", Krishnan. V. ${ }^{2}$, Anila. S. ${ }^{3}$, Annie. V. Issac ${ }^{4}$ \\ ${ }^{1}$ Reader, ${ }^{2,3}$ Professor, ${ }^{4}$ Senior Lecturer, Dept. of Periodontics, ${ }^{1,3,4}$ St. Gregorios Dental College, Kerala, ${ }^{2}$ Rajah Muthiah Dental \\ College, Annamalai University, Tamil Nadu
}

*Corresponding Author:

Email: swarooprini@gmail.com

\begin{abstract}
Introduction: Periodontitis is an inflammatory disease often chronic in nature characterized by destruction of both hard and soft tissues surrounding the teeth which may eventually lead to loss of teeth. Periodontitis results from immune inflammatory response to certain gram negative anaerobes in a susceptible host.

Aim: The aim of the present study was to evaluate peripheral blood levels in healthy subjects, chronic and aggressive periodontitis patients and to assess whether increased levels of periodontal parameters in these subjects with chronic and aggressive periodontitis can influence the peripheral blood levels in the three study groups.

Materials and Methods: The study was carried out on 55 subjects with male and female ratios of 27: 28 and included 20 controls, 20 patients with chronic periodontitis (Both localized and generalized cases) and 5 localized and 10 generalized aggressive periodontitis patients. Blood samples were collected from healthy controls $(\mathrm{n}=20)$ and patients with chronic periodontitis $(n=20)$ and aggressive periodontitis $(n=15)$. Recording of Oral Hygiene Index-Simplified $(\mathrm{OHI}-\mathrm{S})$, Bleeding Index (BI), Probing Pocket Depth (PPD) and Clinical Attachment Level (CAL) was done to evaluate the periodontal status of each patient. Blood was collected and transported to a lab within four hours after venepuncture for processing and peripheral blood parameters were evaluated. Data presentation was done in the form of mean and standard deviation and analysis of data was done using one way ANOVA and Students t-test to test the statistical significance between study groups.

Results: An increase in peripheral blood levels of WBC and platelets were observed in both study groups whereas RBC and hemoglobin level were found to decrease in both the study groups when compared to healthy controls and this was found to be statistically significant $(\mathrm{P}<0.001)$.

Conclusion: The findings of the present study indicates that there is a statistically significant correlation between presence and intensity of periodontitis and peripheral blood levels.
\end{abstract}

Keywords: Hemoglobin, Periodontal parameters, Platelets, Red blood cell, White blood cell.

\section{Introduction}

Periodontitis is an infectious and inflammatory disease often chronic and multifactorial in nature characterized by destruction of periodontium surrounding the teeth which may eventually lead to loss of both hard and soft tissue supporting structures ${ }^{1}$. Gram negative pathogens such as $A$. actinomycetemcomitans, $P$. gingivalis and $T$. forsythia can initiate subgingival infection leading to periodontal disease $^{2}$. Inflammation of supporting tissues can lead to ulceration of the epithelium and pathological deepening of the sulcus which can act as portal of entry and pathway for transient bacteremias. These transient bacteremias can lead to the production of proinflammatory mediators like TNF- $\alpha$, IL- $1 \beta$, IL- 6 and $\mathrm{C}$-reactive protein which can further aggravate tissue destruction. ${ }^{2,3}$

The two main types of periodontitis are chronic and aggressive periodontitis which can be differentiated based age of onset, rapid rate of disease progression, nature and composition of associated subgingival microflora, alterations in host tissue response and familial aggregation of diseased individuals. ${ }^{4}$

Various studies ${ }^{1,3}$ have stressed the importance of blood as an ultimate body fluid that could indicate an ongoing disease process. An inflammatory condition or infection which can be a risk factor for various systemic diseases can be diagnosed based on the total number of white blood cells in peripheral blood. ${ }^{5}$ Higher number of leukocytes make blood more viscous and decrease the blood flow by adhering to the endothelial cells lining the blood vessels. Reduction in blood flow especially in narrow or blocked arteries due to atherosclerotic plaque formation can be an important etiologic factor for various cardiovascular diseases. ${ }^{6,7}$

An increase in number of active thrombocytes can occur in inflammatory and infectious process and this is known as "Reactive Thrombocytosis". 8 Periodontal pathogens such as $P$. gingivalis and $A$. actinomycetemcomitans can activate thrombocytes which occurs mainly in the granulation tissue where thrombocytes internalize bacteria or bacterial antigens and as a result produce antimicrobial peptides and cytokines. Platelet leukocyte complexes (plateletneutrophil and platelet - monocyte) are sensitive markers for platelet activation and plays an important role in thrombosis and inflammation. Platelet activation can occur in various inflammatory diseases such as arterial thrombosis, asthma, rheumatoid arthritis and subsequent coronary vascular and cerebro-vascular diseases. ${ }^{9,10}$ 
Anemia of chronic disease is a phenomenon which has been found to be associated with acute or chronic immune activation and occurs during chronic infection, inflammatory process or tumour formation despite adequate iron and vitamin intake. ${ }^{11}$ ACD is a multifactorial anemia that is most prevalent form after iron deficiency anemia occurring in conditions such as chronic renal disease, chronic obstructive pulmonary disease and rheumatoid arthritis ${ }^{3}$. It is a normocytic /normochromic anemia characterized by normal or increased iron stores with decreased serum iron and total iron binding capacity. ${ }^{12}$ ACD is charecterized by decreased survival rate of $\mathrm{RBC}$, defective erythropoiesis that can lead to impaired erythropoietic response and decreased reticuloendothelial iron stores for haemoglobin synthesis. ${ }^{13,14}$ The underlying pathophysiology can be attributed to inability to release iron by macrophages that normally occurs during breakdown of senescent RBCs. ${ }^{15,16}$

Hematocrit is a measure (in percentage) of relative volume occupied by erythrocytes in whole blood. Periodontitis is a low grade systemic inflammation and lower hematocrit in periodontitis was explained by lower number of erythrocytes in their blood. ${ }^{12,17}$

Therefore, this study was carried out to evaluate peripheral blood levels in healthy subjects, chronic and aggressive periodontitis patients and whether increased levels of periodontal parameters in these subjects can influence the peripheral blood levels in the three study groups.

\section{Materials and Methods}

The present study was a cross-sectional descriptive study conducted in the Division of Periodontology, St Gregorios Dental College, Kothamangalam, Kerala for a period of 6 months. A pilot study was undertaken for a period of one month inorder to determine the correct sample size based on which the subjects were selected for the final study. A thorough medical history was obtained from the participants taking part in the study and were screened for periodontal examination. A single calibrated investigator undertook the evaluation of all periodontal parameters included in the study. The study was carried out on 55 subjects with male and female ratios of 27:28 and included 20 controls, 20 patients with chronic periodontitis and 5 Localized and 10 generalized aggressive periodontitis patients. The number of aggressive periodontitis patients had to be limited to 15 due to constraints in obtaining aggressive periodontitis patients within the stipulated period of study.

(The pilot study was done using 15 subjects which consisted of five healthy, five chronic and five aggressive periodontitis patients.)

(The sample size was calculated using the formula $\frac{n}{1+\mathrm{ne}^{2}}$ where $\mathrm{n}$ is the total population taken and $\mathrm{e}$ is the standard error $(e=0.05)$. Since there were constraints in obtaining aggressive periodontitis patients (localized \& generalized) within time period of the study (6 months), their sample size had to be restricted to 15 . Therefore the control and the chronic periodontitis group had to be limited to 20 each. So $\mathrm{n}$ was taken as 60 and using this formula minimum sample size obtained was 52. Based on this, the total sample size was fixed at 55.)

An informed consent was obtained from the patients after explaining the nature and purpose of study and ethical committee clearance was also obtained prior to the study.

Subjects for this study were divided into 3 groups consisting of Group A which included systemically and periodontally Healthy Controls of age group between 25-45 years with PPD $\leq 3 \mathrm{~mm}, \mathrm{CAL}<2 \mathrm{~mm}$ and having no clinical signs of inflammation, Group B including chronic periodontitis patients of age group between 3045 years having more than $30 \%$ of their teeth with PPD $\geq 4 \mathrm{~mm}$ and $\mathrm{CAL} \geq 2 \mathrm{~mm}^{4}$ and Group $\mathrm{C}$ including Generalized \& Localized Aggressive Periodontitis patients between age group 20-35 years. Other criteria for group $\mathrm{C}$ included minimum of 20 remaining teeth with a pattern of generalized interproximal attachment loss affecting at least 3 permanent teeth other than 1st molars \& incisors (Gen AgP) / localized first molar or incisor presentation with interproximal attachment loss on at least 2 permanent teeth, one of which is a first molar and involving no more than two teeth other than 1st molars and incisors. The amount of tissue destruction cannot be correlated with volume of deposits present. ${ }^{4}$

Study included systemically healthy individuals of both genders having atleast 20 functioning teeth without undergoing any periodontal surgical/non surgical procedure or taking any antibiotics, systemic steroids or anti-inflammatory drugs 6 months prior to and during the period of study. Subjects who were females, alcoholics, smokers, suffering from cardiovascular diseases, diabetes and having any form of ongoing acute/chronic viral, fungal or bacterial infections were not included in the study

The subjects in the study were evaluated for the following clinical parameters which included OHI-S (Green \& Vermillion 1964), ${ }^{18}$ Gingival Bleeding Index (Ainamo \& Bay 1975), ${ }^{19}$ Probing Pocket Depth (PPD) and Clinical Attachment Level (CAL).

Estimation of Peripheral Blood: Collection of samples were carried out after obtaining the consent of the subject. Using a $5 \mathrm{ml}$ syringe, $3 \mathrm{ml}$ of blood was collected from anticubital fossa by venipuncture using 20 gauge needle during the morning hours. The blood was transferred to EDTA containing test tubes for routine investigation of $\mathrm{RBC}, \mathrm{WBC}$, Platelets and Hemoglobin in peripheral blood. 


\section{Statistical Analysis}

SPSS package version 14.0 software programs was used for analysing the collected data. Data description was done in the form of mean \pm standard deviation and analysis of data was done to test the statistical significance between groups. The following statistical tools were used to analyse the data. They were

1. One-way ANOVA (Analysis of Variance) was applied to compare the mean values of OHI-S, BI, PPD, CAL, WBC, PLATELETS, RBC and $\mathrm{Hb}$ among three groups.

2. Students t-test was applied to compare the mean values of OHI-S, BI, PPD, CAL, WBC, PLATELETS, $\mathrm{RBC}$ and $\mathrm{Hb}$ between two groups.

$\mathrm{p}$ values $\leq 0.05$ were considered to be statistically significant.

\section{Results}

The results obtained were tabulated and subjected to statistical analysis through one-way ANOVA and students t-test and the following results were drawn:

In the present study, chronic periodontitis patients were found to have higher mean OHI-S, BI score, mean PPD and CAL when compared to patients with aggressive periodontitis and systemically and periodontally healthy individuals (Table 1). The mean White Blood Cell levels were found to be higher in aggressive periodontitis patients $(8686.67 \pm 956.83$ cell/cumm) when compared with chronic periodontitis patients $(8635.00 \pm 928.09$ cell/cumm $)$ and periodontally healthy subjects $(8065.00 \pm 687.69$ cell/cumm; $\mathrm{p}<0.001)$. The mean Platelet levels were found to be higher in aggressive periodontitis patients
$(2.140 \pm 0.414$ lakh/cumm) when compared with chronic periodontitis patients $(2.074 \pm 0.381$ lakh/cumm) and periodontally healthy subjects $(1.770 \pm$ $0.501 \mathrm{lakh} / \mathrm{cumm} ; \mathrm{p}<0.05)$. The mean Red Blood Cell levels were found to be higher in periodontally healthy subjects $(4.7060 \quad \pm 0.3790 \quad$ million/cumm $)$ when compared with chronic periodontitis $(4.1245 \pm 0.3438$ million/cumm) and aggressive periodontitis patients $(4.1193 \pm 0.2735 \mathrm{million} / \mathrm{cumm} ; \mathrm{p}<0.001)$. The mean Hemoglobin levels were found to be higher in periodontally healthy subjects $(11.40 \pm 1.84 \mathrm{gm} / \mathrm{dl})$ when compared with chronic periodontitis $(9.53 \pm 1.12$ $\mathrm{gm} / \mathrm{dl})$ and aggressive periodontitis patients $(9.59 \pm$ $1.21 \mathrm{gm} / \mathrm{dl} ; \mathrm{p}<0.001$ ) (Table 1). There was no statistically significant difference in the mean values of WBC, PLATELETS, RBC \& HAEMOGLOBIN when chronic and aggressive periodontitis patients were compared $(\mathrm{p} \geq 0.05)$ (Table 2). An increase in level of $\mathrm{WBC}$ and platelets were found in aggressive periodontitis group when compared with other groups and this was found to be statistically significant $(\mathrm{p}<0.001)$ (Table $3 \&$ Table 4). An increase in level of RBC and hemoglobin were found in healthy controls when compared with study groups and this was found to be statistically significant $(\mathrm{p}<0.001)$. (Table 3 \& Table 4).

A positive correlation exists between levels of clinical parameters like oral hygiene index-simplified, bleeding index, probing pocket depth, clinical attachment level and the study groups $(\mathrm{p}<0.001)$. (Table $5 \&$ Table 6).

Table 1: One way ANOVA test showing mean and standard deviation of OHI-S, bleeding index, probing pocket depth level, clinical attachment level, WBC, platelet, RBC and hemoglobin level between three groups

\begin{tabular}{|c|c|c|c|c|c|c|}
\hline \\
\hline & Groups & $\mathbf{N}$ & Mean & SD & F-value & P - Val ue \\
\hline \multirow[b]{3}{*}{ OHI-S } & $\mathrm{A}$ & 20 & 0.62 & 0.22 & \multirow{3}{*}{9.83} & \multirow{3}{*}{$\begin{array}{c}0.001 \\
\text { (Significant) }\end{array}$} \\
\hline & $\mathrm{B}$ & 20 & 4.00 & 0.61 & & \\
\hline & $\mathrm{C}$ & 15 & 2.27 & 0.49 & & \\
\hline \multirow[b]{3}{*}{ BI } & A & 20 & 0.440 & 0.660 & \multirow[t]{3}{*}{42.31} & \multirow{3}{*}{$\begin{array}{c}0.001 \\
\text { (Significant) }\end{array}$} \\
\hline & $\mathrm{B}$ & 20 & 85.120 & 6.067 & & \\
\hline & $\mathrm{C}$ & 15 & 69.013 & 8.123 & & \\
\hline \multirow[b]{3}{*}{ PPD (mm) } & A & 20 & 2.375 & 0.297 & \multirow[t]{3}{*}{11.32} & \multirow{3}{*}{$\begin{array}{c}0.001 \\
\text { (Significant) }\end{array}$} \\
\hline & $\mathrm{B}$ & 20 & 5.735 & 0.854 & & \\
\hline & $\mathrm{C}$ & 15 & 5.527 & 0.446 & & \\
\hline \multirow[b]{3}{*}{ CAL (mm) } & A & 20 & 0.00 & 0.00 & \multirow[t]{3}{*}{24.86} & \multirow{3}{*}{$\begin{array}{c}0.001 \\
\text { (Significant) }\end{array}$} \\
\hline & B & 20 & 5.93 & 0.39 & & \\
\hline & $\mathrm{C}$ & 15 & 5.41 & 0.81 & & \\
\hline \multirow[b]{3}{*}{$\mathrm{WBC}($ cell/cumm) } & $\mathrm{A}$ & 20 & 8065.00 & 687.69 & \multirow[t]{3}{*}{4.63} & \multirow{3}{*}{$\begin{array}{c}0.001 \\
\text { (Significant) }\end{array}$} \\
\hline & B & 20 & 8635.00 & 928.09 & & \\
\hline & $\mathrm{C}$ & 15 & 8686.67 & 956.83 & & \\
\hline \multirow{3}{*}{$\begin{array}{l}\text { PLATELET } \\
\text { (lakh/cumm) }\end{array}$} & A & 20 & 1.770 & 0.501 & \multirow[t]{3}{*}{3.57} & \multirow{3}{*}{$\begin{array}{c}0.05 \\
\text { (Significant) }\end{array}$} \\
\hline & B & 20 & 2.074 & 0.381 & & \\
\hline & $\mathrm{C}$ & 15 & 2.140 & 0.414 & & \\
\hline \multirow[b]{2}{*}{$\mathrm{RBC}$} & A & 20 & 4.7060 & 0.3790 & \multirow[t]{2}{*}{3.12} & \multirow{2}{*}{$\begin{array}{c}0.001 \\
\text { (Significant) }\end{array}$} \\
\hline & $\mathrm{B}$ & 20 & 4.1245 & 0.3438 & & \\
\hline
\end{tabular}




\begin{tabular}{|l|c|c|c|c|c|c|}
\hline (million/cum) & $\mathrm{C}$ & 15 & 4.1193 & 0.2735 & & \\
\hline \multirow{2}{*}{$\begin{array}{l}\text { HEMOGLOBIN } \\
\text { (gm/dl) }\end{array}$} & $\mathrm{A}$ & 20 & 11.40 & 1.84 & \multirow{2}{*}{4.86} & 0.001 \\
\cline { 2 - 5 } & $\mathrm{B}$ & 20 & 9.53 & 1.12 & & \\
\cline { 2 - 5 } & $\mathrm{C}$ & 15 & 9.59 & 1.21 & & \\
\hline
\end{tabular}

Table 2: Students t-test comparing WBC, Platelet, RBC and hemoglobin level between Group B and Group C

\begin{tabular}{|c|c|c|c|c|c|}
\hline Parameters & Group & $\mathbf{N}$ & Mean & SD & P-Value \\
\hline \multirow{2}{*}{$\begin{array}{l}\text { WBC } \\
\text { (cell/cumm) }\end{array}$} & B & 20 & 8635.00 & 928.09 & \multirow{2}{*}{ Not Significant } \\
\hline & $\mathrm{C}$ & 15 & 8686.67 & 956.83 & \\
\hline \multirow{2}{*}{$\begin{array}{l}\text { Platelets } \\
\text { (lakh/cumm) }\end{array}$} & $\mathrm{B}$ & 20 & 2.074 & 0.381 & \multirow{2}{*}{ Not Significant } \\
\hline & $\mathrm{C}$ & 15 & 2.140 & 0.414 & \\
\hline \multirow{2}{*}{$\begin{array}{l}\text { RBC } \\
\text { (million/cumm) }\end{array}$} & $\mathrm{B}$ & 20 & 4.1245 & 0.3438 & \multirow{2}{*}{ Not Significant } \\
\hline & $\mathrm{C}$ & 15 & 4.1193 & 0.2735 & \\
\hline \multirow{2}{*}{$\begin{array}{l}\text { Hemoglobin } \\
(\mathrm{gm} / \mathrm{dl})\end{array}$} & B & 20 & 9.53 & 1.12 & \multirow{2}{*}{ Not Significant } \\
\hline & $\mathrm{C}$ & 15 & 9.59 & 1.21 & \\
\hline
\end{tabular}

Table 3: Students t-test comparing WBC, platelet, RBC and hemoglobin level between Group A and Group B

\begin{tabular}{|c|c|c|c|c|c|}
\hline Parameters & Group & $\mathbf{N}$ & Mean & SD & P-Value \\
\hline \multirow{2}{*}{ WBC (cell/cumm) } & $\bar{A}$ & 20 & 8065.00 & 687.69 & \multirow{2}{*}{0.03 (Significant) } \\
\hline & B & 20 & 8635.00 & 928.09 & \\
\hline \multirow{2}{*}{ Platelet (lakh/cumm) } & A & 20 & 1.770 & 0.501 & \multirow{2}{*}{0.03 (Significant) } \\
\hline & B & 20 & 2.074 & 0.381 & \\
\hline \multirow{2}{*}{$\begin{array}{l}\mathrm{RBC} \\
\text { (million/cumm) }\end{array}$} & A & 20 & 4.7060 & 0.3790 & \multirow{2}{*}{0.001 (Significant) } \\
\hline & B & 20 & 4.1245 & 0.3438 & \\
\hline \multirow{2}{*}{ Hemoglobin $(\mathrm{gm} / \mathrm{dl})$} & A & 20 & 11.40 & 1.84 & \multirow{2}{*}{0.001 (Significant) } \\
\hline & $\mathrm{B}$ & 20 & 9.53 & 1.12 & \\
\hline
\end{tabular}

Table 4: Students t-test comparing WBC, Platelet, RBC and hemoglobin level between Group A and Group C

\begin{tabular}{|c|c|c|c|c|c|}
\hline Parameters & Group & $\mathbf{N}$ & Mean & SD & P-Value \\
\hline \multirow{2}{*}{ WBC(cell/cumm) } & $\mathrm{A}$ & 20 & 8065.00 & 687.69 & \multirow{2}{*}{0.05 (Significant) } \\
\hline & $\mathrm{C}$ & 15 & 8686.67 & 956.83 & \\
\hline \multirow{2}{*}{ Platelet(lakh/cumm) } & $\mathrm{A}$ & 20 & 1.770 & 0.501 & \multirow{2}{*}{0.03 (Significant) } \\
\hline & $\mathrm{C}$ & 15 & 2.140 & 0.414 & \\
\hline \multirow{2}{*}{$\mathrm{RBC}(\mathrm{million} / \mathrm{cumm})$} & $\mathrm{A}$ & 20 & 4.7060 & 0.3790 & \multirow{2}{*}{0.001 (Significant) } \\
\hline & $\mathrm{C}$ & 15 & 4.1193 & 0.2735 & \\
\hline \multirow{2}{*}{ Hemoglobin(gm/dl) } & $\mathrm{A}$ & 20 & 11.40 & 1.84 & \multirow{2}{*}{0.001 (Significant) } \\
\hline & $\mathrm{C}$ & 15 & 9.59 & 1.21 & \\
\hline
\end{tabular}

Table 5: Students t-test comparing different periodontal parameters between Group A and Group B

\begin{tabular}{|c|c|c|c|c|c|}
\hline \begin{tabular}{|l} 
Clinical \\
Parameters
\end{tabular} & Group & $\mathbf{N}$ & Mean & SD & P-Value \\
\hline \multirow{2}{*}{ OHI-S } & A & 20 & 0.62 & 0.22 & \multirow{2}{*}{0.001 (Significant) } \\
\hline & B & 20 & 4.00 & 0.61 & \\
\hline \multirow{2}{*}{ BI } & A & 20 & 0.440 & 0.611 & \multirow{2}{*}{$\begin{array}{c}0.001 \\
\text { (Significant) }\end{array}$} \\
\hline & B & 20 & 85.120 & 6.067 & \\
\hline \multirow{2}{*}{ PPD (mm) } & A & 20 & 2.375 & 0.297 & \multirow{2}{*}{0.001 (Significant) } \\
\hline & B & 20 & 5.735 & 0.854 & \\
\hline \multirow{2}{*}{$\mathrm{CAL}(\mathrm{mm})$} & A & 20 & 0.00 & 0.00 & \multirow{2}{*}{0.001 (Significant) } \\
\hline & B & 20 & 5.93 & 0.39 & \\
\hline
\end{tabular}

Table 6: Students t-test comparing different periodontal parameters between Group A and Group C

\begin{tabular}{|l|c|c|c|c|c|}
\hline $\begin{array}{l}\text { Periodontal } \\
\text { Parameters }\end{array}$ & Group & N & Mean & SD & P- Value \\
\hline \multirow{2}{*}{ OHI-S } & A & 20 & 0.62 & 0.22 & \multirow{2}{*}{0.001 (Significant) } \\
\cline { 2 - 5 } & C & 15 & 2.27 & 0.49 & \\
\hline BI & A & 20 & 0.440 & 0.611 & 0.001 (Significant) \\
\hline
\end{tabular}




\begin{tabular}{|l|c|c|c|c|c|}
\hline & C & 15 & 69.013 & 8.132 & \\
\hline \multirow{2}{*}{ PPD $(\mathrm{mm})$} & A & 20 & 2.375 & 0.297 & \multirow{2}{*}{0.001 (Significant) } \\
\cline { 2 - 5 } & C & 15 & 5.527 & 0.446 & \\
\cline { 2 - 5 } CAL $(\mathrm{mm})$ & $\mathrm{A}$ & 20 & 0.00 & 0.00 & 0.001 (Significant) \\
\cline { 2 - 5 } & $\mathrm{C}$ & 15 & 5.41 & 0.18 & \\
\hline
\end{tabular}

number of active thrombocytes during inflammatory

The study shows a positive correlation between the presence of periodontitis and peripheral blood levels, but fails to show any clear association between periodontitis and systemic diseases. Therefore the inclusion of a larger study population with evaluation of serum ferritin levels and post treatment results could provide a better insight and understanding into the association between periodontitis, anemia and cardiovascular diseases.

\section{Discussion}

Periodontitis is an infectious and inflammatory disease of the supporting tissues of the teeth, characterized by loss of soft tissue and tooth supporting alveolar bone. Poor oral hygiene, underlying pathogenic microflora and individual host immune response are the main factors which contributes to initiation and progression of periodontal diseases.

In the present study, mean white blood cell levels were found to be higher in aggressive periodontitis patients when compared with chronic periodontitis patients and periodontally healthy subjects.This is in accordance with studies done by Al-Rasheed $\mathrm{A}^{6}$ and Rai B et al ${ }^{1,20}$ who found elevated levels of mean WBC in periodontitis patients when compared with healthy controls. A probable reason for the results could be, due to the fact that neutrophil is a major cellular component of human innate defence mechanism, against bacterial infections or inflammatory diseases and can perpetuate vascular injury and ischemia(Ernst et al). ${ }^{8,21}$ An elevated total white blood cell count is a risk factor for atherosclerotic progression, and can be induced in patients with infections such as periodontal disease and promote atherosclerosis at distant site, particularly in areas of disturbed blood flow (Johnstone et al, 2007). ${ }^{6}$ Initiation of atherosclerosis by leukocytes occurs by 3 mechanisms including pressure dependent sealing of microvessels, formation of aggregates when provoked by stimuli and by releasing of activated substances including proteolytic enzymes, arachadonic acid metabolites and oxygen-free radicals. ${ }^{7}$

In the present study, mean Platelet levels were found to be higher in aggressive periodontitis patients when compared with chronic periodontitis patients and periodontally healthy subjects. This is in accordance with studies done by Al-Rasheed $\mathrm{A}^{6}$ and Rai B et al ${ }^{1,20}$ who found elevated levels of mean Platelet levels in periodontitis patients when compared with healthy controls. A possible mechanism underlying these results may be the phenomenon of "Reactive Thrombocytosis"which can result in an increase in and infectious process. Periodontal pathogens including Porphyromonas gingivalis has been found to be associated with platelet activation \& aggregation (Lourbakos et al 2001). Activated platelets regulate chemokine release and are primarly involved in hemostasis, endothelial repair and also play an important role in atherogenesis and thrombus formation. ${ }^{9,10,22}$ Platelet activation can occur in various inflammatory diseases such as arterial thrombosis, asthma, rheumatoid arthritis and subsequent coronary vascular and cerebro-vascular diseases..$^{23}$

In the present study, mean Red Blood Cell levels were found to be higher in periodontally healthy subjects when compared with chronic periodontitis and aggressive periodontitis patients. This is in accordance with studies done by Vidya $\mathrm{N}$ et $\mathrm{al}^{24}$ and Rai $\mathrm{B}$ et $\mathrm{al}^{1,8}$ who found elevated levels of mean $\mathrm{RBC}$ in periodontally healthy subjects when compared with periodontitis patients. Studies by Siege ${ }^{25}$ and Chawla reported a depression in erythrocytes secondary to periodontal disease whereas studies by Wakai et al, ${ }^{27}$ Havemose- poulsen et $\mathrm{al}^{28}$ and shobha et $\mathrm{al}^{29}$ failed to show any association between periodontitis and Hemoglobin levels. A possible mechanism underlying these results may be the presence of increased production of cytokines that mediate the immune or inflammatory response such as tumor necrosis factor, interleukin-1 and interferon associated with Anemia of Chronic Disease(ACD). These cytokines are also released within gingival connective tissue resulting in inhibition of erythropoietin and their increased blood levels can aggrevate or perpectuate a systemic condition. Inhibition of erythropoietin, hormone responsible for erythropoiesis can lead to decrease in RBC count. ${ }^{30}$

In the present study, mean Hemoglobin levels were found to be higher in periodontally healthy subjects when compared with chronic periodontitis and aggressive periodontitis patients. This is in accordance with studies done by Vidya $\mathrm{N}$ et $\mathrm{al}^{24}$ and Rai $\mathrm{B}$ et $\mathrm{al}^{1,8}$ who found elevated levels of mean RBC levels in periodontally healthy subjects when compared with periodontitis patients. These results were similar to a study done by Hutter ${ }^{31}$ and Thomas (2006), ${ }^{32}$ where periodontitis patients were found to have a lower hematocrit, lower numbers of erythrocytes, lower hemoglobin levels and higher erythrocyte sedimentation rates.

There were no statistically significant results when peripheral blood levels such as WBC, Platelet, RBC and Hemoglobin were compared in patients with chronic and aggressive periodontitis. To the best of our 
knowledge, no supporting articles were available in the literature to substantiate the above results.

\section{Limitations}

One of the limitations of this study was the non evaluation of serum ferritin levels and soluble serum transferring receptor concentration used to quantify iron stores which clearly distinguishes between iron deficiency anemia \& ACD. Another limitation was the small sample size of aggressive periodontitis patients due to strict guidelines for recruiting the patients under the stipulated period of study. Inclusion of females in the study could have led to bias as females were more prone to hormonal imbalance during puberty, reproductive phase and also increased menstrual losses. Non evaluation of post treatment results also acts as a major factor which could influence the results of the present study. The exclusion of systemic conditions such as diabetes were based on patient reported histories and there is a possibility that this might have led to undiagnosed medical conditions. Non evaluation of parameters pertaining to cardiovascular diseases and anemia fails to provide any clear association between these systemic diseases and periodontitis.

\section{Conclusion}

A positive correlation was found between levels of clinical parameters like oral hygiene index-simplified, bleeding index, probing pocket depth, clinical attachment level and the study groups including chronic and aggressive periodontitis patients. An increase in peripheral blood levels of WBC and platelets were observed in both study groups whereas RBC and hemoglobin level were found to decrease in both the study groups when compared to healthy controls. Management of periodontitis may be an important intervention to modify peripheral blood markers therby reducing the risk of cardiovascular diseases. Therefore evaluation of peripheral blood levels can provide valuable information about the presence and intensity of inflammatory process and further studies with more parameters can provide better insight into association between periodontitis and systemic diseases.

\section{References}

1. Rai B, Kharb S, Jain R, Anand SC. Periodontitis, CReactive Protein and Peripheral Blood; Links with Cardiovascular Disease. Advances in Medical and Dental Sciences. 2010;3(3):76-79.

2. Perumal R, Rajendran M, Krishnamurthy M, Ganji KK, Pendor SD. Modulation of P-selection and platelet aggregation in chronic periodontitis: A clinical study. JISP 2014;18 (3):293-300.

3. Anumolu VSH, Srikanth A. Paidi K. Evaluation of the relation between anemia and periodontitis by estimation of blood parameters: A cross sectional study. JISP 2016;20:265-72.

4. Newman GM, Takei HH, Klokkevold PR, Carranza FA. Carranza's Clinical Periodontology. Vol 10:507-09.
5. Sharma S, Gupta R, Gupta I, Gokhale ST. Effect of nonsurgical therapy on WBC count in generalized chronic periodontitis patients. International journal of scientific study 2013;1(2):36-39.

6. Al-Rasheed A. Elevation of white blood cells and platelet counts in patients having chronic periodontitis. Saudi Dental Journal. 2012:24;17-21.

7. Kumar BP, Khaitan T, Ramaswamy P, Sreenivasulu P, Uday G, Velugubantla RG et al. Association of chronic periodontitis and white blood cell and platelet count- a case control study. Journal of Clinical and Experimental Dentistry. 2014;6(3):214-217.

8. Rai B, Kaur J, Kharb S, Jain R, Anand SC, Singh J et al. Peripheral blood and CRP levels in chronic periodontitis. African journal of Biochemistry research 2009;3(4):150153.

9. Papapanagiotou D, Nicu EA, Bizzarro S, Gerdes VEA, Meijers JC, Nieuwland R et al. Periodontitis is associated with platelet activation. Atherosclerosis 202 (2009):605611.

10. 24. Nicu EA, Van der velden U, Nieuwland R, Everts and Loos BG. Elevated platelet and leukocyte reponse to oral bacteria in periodontitis. Journal of Thrombosis and Haemostasis 2008;7:162-170.

11. Agarwal N, Kumar VSC, Gujjari SA. Effect of periodontal therapy on haemoglobin and erythrocyte levels in chronic generalized periodontitis patients: An interventional study. JISP 2009;13(1);6-11.

12. Patel MD, Shakir QJ, Shetty A. Interrelationship between chronic periodontitis and anemia: A 6- month follow-up study. JISP 2014;18(1):19-24.

13. Aljohani HA. Association between haemoglobin level and severity of chronic periodontitis. Journal of King Abdulaziz University- Science: 2010;2010 17 (1):53-64.

14. Malhotra R, Kapoor A, Grover V, Grover D, Kaur A. Effect of scaling and root planning on erythrocyte count, haemoglobin and haematocrit in patients with chronic periodontitis. The journal of dental hygiene 2012;86(3):195-203.

15. Shin-Yu Lu, Hock-Liew Eng. Dramatic recovery from severe anemia by resolution of severe periodontitis. Journal of Dental Sciences. 2010;5(1):41-46.

16. Weiss GMD, Goodnough LT. Anemia of chronic disease. New England Journal of Medicine. 2005;352:1011-23.

17. Hegde S, Riyas, Kashyap R, Kumar AMS. Comparitive evaluation of blood parameters in chronic periodontitis patients and healthy patients for signs of anemia. Journal of dental and medical sciences 2014;13(12)30-36.

18. Shabani LF, Begzati A, Dragidella F, Hoxha VH, Cakolli $\mathrm{VH}$, Bruci B. The correlation between DMFT and OHI-S Index among 10-15-year-old children in Kosova. Journal of Dental and Oral Health. 2015;1(1):1-5.

19. Rebelo MAB, de Queiroz AC. Gingival Indices: State of Art. www.intechopen.com.41-54.

20. Rai B, Anand SC. After Scaling and Root planning lower systemic inflammatory and Thrombotic marker of cardiovascular risk. Middle - East Journal of Scientific Research 2007;2(2):54-56.

21. Imaki M, Ogawa Y, Yoshida Y, Uchida M, Tanada S. Cohort study of the total leukocyte count and periodontal disease among company employees. Environmental Health and Preventive Medicine 1999;4:54-57.

22. Kamath S, Blann AD, Lip GYH. Platelet activation : assessment and quantification. European Heart Journal 2001;22:1561-1571.

23. Klinger MHF, Jelkmann W. Role of Blood Platelets in infection and inflammation. Journal of interferon \& Cytokine Research 2002;22:913-922. 
24. Vidya N, Acharya A, Deshmukh VL, Shetty S.

Generalized, severe, chronic periodontitis is associated with anemia of chronic disease: a pilot study in urban, Indian males. Journal of Investigative and Clinical Dentistry2010;1:139-134.

25. Siegel EH. Total erythrocyte, leucocyte and differential white cell counts of blood in chronic periodontal disease. Journal of Dental Research 1945;24: 270-1.

26. Chawla TN, Kapoor KK, Teotia SP, Singh NK. Anemia and periodontal disease-a correlative study. Journal of Indian Dental Association.1971;43:67-78.

27. Wakai K, Kawamura T, Umemura O, Hara Y, Machida J, Anno T et al. Associations of medical status and physical fitness with periodontal disease. Journal of Clinical Periodontology. 1999;26:664-72.

28. Havmose -Poulsen A, Wetergaard J, Stolze K, Skjodt H, Danneskiold - Samsoe, Locht H et al. Periodontal and haematological characterestics associated with aggressive periodontitis, juvenile idiopathic arthritis and rheumatoid arthritis. Journal of Periodontology. 2006;77:280-8.

29. Prakash S, Dhingra K, Priya S. Similar haematological and biochemical parameters among periodontitis and control group subjects. European Journal of Dentistry. 2012;6:287-294.

30. Mishra P, Agarwal S, Devraj CG, Nayak PA, Yadav A, Sharma S. Determination of Erythrocyte parameters in Chronic periodontitis patients. International journal of Medical Science and education. 2014;1(3):148-154.

31. Hutter JW, Van der Velden U, Varoufaki A, Huffels RAM, Hoek FJ, Loos BG. Lower number of erythrocytes and lower levels of haemoglobin in periodontitis patients compared to control subjects. Journal of Clinical Periodontology 2001;28: 930-936.

32. Thomas B, Ramesh A, Rithesh K. Relationship between periodontitis and erythrocyte count. JISP 2006;10:288291. 